\title{
Conjunctival repair after glaucoma drainage device exposure using collagen-glycosaminoglycane matrices
}

\author{
André Rosentreter ${ }^{*^{*}}$ (D) Alexandra Lappas ${ }^{2}$, Randolf Alexander Widder ${ }^{3}$, Maged Alnawaiseh ${ }^{4}$ \\ and Thomas Stefan Dietlein ${ }^{2}$
}

\begin{abstract}
Background: To report the results of the repair of conjunctival erosions resulting from glaucoma drainage device surgery using collagen-glycosaminoglycane matrices (CGM).

Methods: Case series of 8 patients who underwent revision surgery due to conjunctival defects with exposed tubes through necrosis of the overlying scleral flap and conjunctiva after Baerveldt drainage device surgery. The defects were repaired by lateral displacement of the tube towards the sclera, with a slice of a CGM as a patch, covered by adjacent conjunctiva.
\end{abstract}

Result: Successful, lasting closure (follow-up of 12 to 42 months) of the conjunctival defects was achieved without any side-effects or complications in all eight cases.

Conclusions: Erosion of the drainage tube, creating buttonholes in the conjunctiva after implantation of glaucoma drainage devices, is a potentially serious problem. It can be managed successfully using a biodegradable CGM as a patch.

Keywords: Episcleral drainage device, Baerveldt, Ahmed, Collagen-glycosaminoglycane matrix (CGM), Drainage tube, Conjunctival defect, Conjunctival repair, Conjunctival hole, Glaucoma drainage device, Biodegradable implant, Ologen implant

\section{Background}

Conjunctival defects after penetrating glaucoma surgery, e.g. trabeculectomy or insertion of episcleral glaucoma drainage devices, are rare but severe complications. The defects often lead to leakage and contact between the anterior chamber and surrounding surfaces with the risk of subsequent carry-over of bacteria, blebitis and endophthalmitis [1-5].

In the case of trabeculectomy, especially after use of antimetabolites such as mitomycin-C (MMC) and 5fluoruracile (5-FU), conjunctival defects can even occur a long time after surgery. Antimetabolites, which are very useful for prevention of scarring, affect wound healing processes and lead to the formation of thinwalled blebs [6].

\footnotetext{
* Correspondence: andre.rosentreter@googlemail.com

${ }^{1}$ Department of Ophthalmology, University of Würzburg, Josef-Schneider-Str. 11, 97080 Würzburg, Germany

Full list of author information is available at the end of the article
}

After implantation of an episcleral glaucoma drainage device (GDD, e.g. the non-valved Baerveldt (Advanced Medical Optics, USA) or the valved Ahmed (New World Medical, USA) etc.), complications such as erosion of the tube (GDD-specific) or even the plate of the implant through the conjunctiva occur in $2-7 \%$ cases [1-5]. As with late bleb leakage after trabeculectomy, erosion of the conjunctiva exposing the tube of the GDD makes revision surgery necessary [7]. Erosion of the conjunctiva on top of the tube or the implant is more frequent in eyes with a history of multiple intraocular surgeries.

To repair erosion of the conjunctiva, a patch is usually placed on top of the tube and the conjunctiva is closed above this patch. Due to the surrounding scar tissue and the fragile structure of the frequently inflamed tissue around the tube, specialist knowledge and skill are required to achieve long-lasting wound closure in conjunctiva surgery. As reported in a case report [8], we favour a combination of re-fixation of the tube to the sclera 
with prior lateral displacement of the tube, followed by patching of the implant with a slice of a biodegradable implant (ologen ${ }^{\mathrm{Ts}}$ implant, Aeon Astron Corporation, The Netherlands) in combination with conjunctival advancement. The aim of the lateral displacement of the tube is to avoid mechanical problems between the tube and lid margin at the previous point of conjunctival erosion, which could trigger repeated conjunctival erosion.

Since only a small number of patients suffer from conjunctival erosion after glaucoma drainage device surgery $(2-7 \%)$ [1-5], we present a case-series of just eight patients who underwent such surgery. We hereby focus not only on the surgical success in covering the defect, but also on intraocular pressure, antiglaucomatous medication, visual acuity and the need for further surgical interventions.

\section{Methods}

\section{Patients and preoperative examination}

Our study was based on a retrospective consecutive case series of eight patients who were treated for buttonholes [Fig. 1a] after glacuoma drainage device surgery between 2009 and 2016 in the Center of Ophthalmology, University of Cologne. Due to the retrospective study design and no further patient examinations, an ethics vote was considered unnecessary ( $\$ 2(1)$ and $(2)$ of the Statutes of the Ethics Committee of the University of Lübeck). All surgeries were performed by an experienced glaucoma surgeon (TD). In all cases, an episcleral glaucoma drainage device was used after several preliminary operations (minimum 2) for intractable glaucoma. After a minimum of 1 month and a maximum of 6 years conjunctival erosion of the tube occurred.

Before surgical intervention, all patients underwent a baseline examination, which included measurement of best-corrected visual acuity (ETDRS charts, Lighthouse, Long Island, USA), visual field examination (30-2, Octopus perimeter 101, Haag-Streit, Switzerland), biomicroscopy, gonioscopy, and Goldmann applanation tonometry.

\section{Surgical technique and follow-up}

The surgical procedure was performed under either general or local anesthesia, according to the patient's preference. As described in our previous publication [8], the tubes were laterally displaced, fixed to the sclera with a horizontal mattress 10-0 nylon suture (knots recessed to the sclera), and covered with a slice of an ologen ${ }^{\mathrm{Th}} \mathrm{im}$ plant of 1-2 mm thickness. The conjunctiva was closed after mobilisation with a rotational flap of adjacent conjunctiva [Fig. 1b \& c; 2]. Postoperatively, the patients received topical antibiotics three times a day for 2 weeks and low-dose steroids three times a day for 3 weeks.

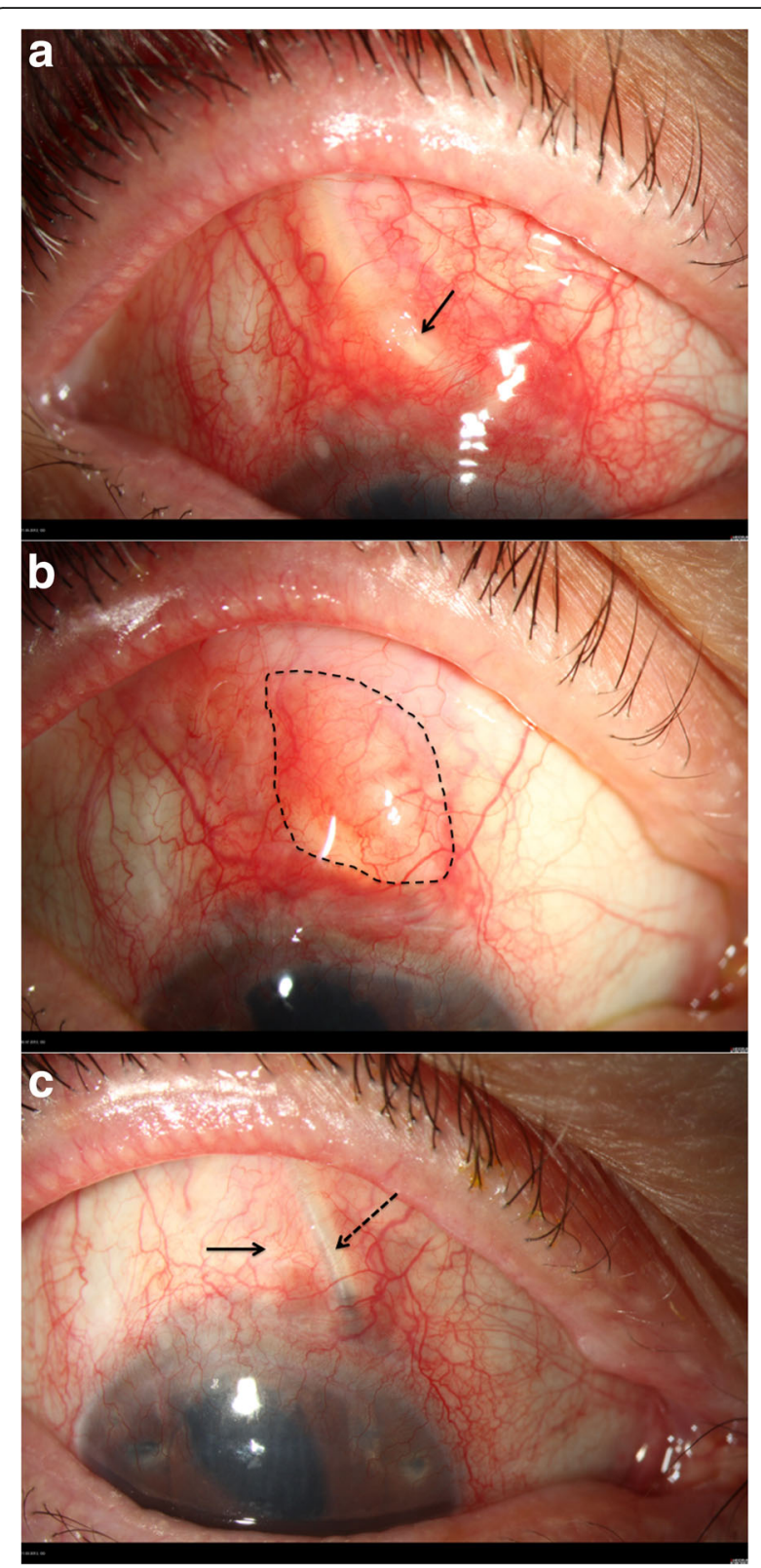

Fig. 1 Chronological order. a Conjunctival buttonhole of $1 \times 0.5 \mathrm{~mm}$ with exposure of the tube; arrow indicates the area of exposure. b Conjunctival defect closed with conjunctival hyperemia and underlying ologen implant at 2 months after surgery; dashed line shows the size of the ologen slice. c Stable re-epithelialisation at 10 months following surgery; arrow indicates the former area of exposure, the dashed arrow shows the displaced tube. The ologen implant has already been resorbed at this time (Complete resorption is usually seen between the third and sixth postoperative months)

Postoperative examinations were performed on a daily basis during hospitalisation. After hospitalisation, followup visits were arranged at 1 and 4 weeks and 3, 6, 12 and 24 months after surgery. At each visit all the abovementioned examinations, except for visual-field testing 
and gonioscopy, were repeated. Side-effects and complications were recorded during postoperative follow-ups.

\section{Ologen ${ }^{\mathrm{TM}}$ implant}

The ologen ${ }^{\text {tu }}$ implant (Aeon Astron Europe B.V., the Netherlands) is a porous implant comprising $>90 \%$ lyophilized porcine atelocollagen and $<10 \%$ lyophilized glycosaminoglycan with a pore size of 20 to $200 \mu \mathrm{m}$ [Fig. 2]. In our study we used a cylindrical (12 mm diameter) implant of $1 \mathrm{~mm}$ in height, either folded or unfolded, and in some cases cut down to a slice of $5 \times 5 \mathrm{~mm}$.

Atelocollagen is a highly purified pepsin-treated type I collagen. A collagen molecule has an amino acid sequence, known as a telopeptide, at both $\mathrm{N}$ - and C-terminals, which confers most of the collagen's antigenicity. Atelocollagen obtained by pepsin treatment is low in immunogenicity, because it is free of telopeptides $[8,9]$.

\section{Statistics}

Primary endpoint and surgical success were defined as complete wound closure without leakage of aqueous humour. Secondary endpoints were IOP control without the need for further revision surgery. Pre- and postoperative antiglaucomatous medication was classified according to a medication score [10].

The datasets used and/or analysed during the current study available are from the corresponding author on reasonable request. Statistical analysis was performed using Prism software (version 5, GraphPad software). Differences between preoperative and postoperative IOP and medication were compared by the non-parametric $t$-test, as the values were considered to be distributed nonparametrically (Mann-Whitney test, two-tailed). $P$-values of less than 0.05 were considered statistically significant.

\section{Results}

In most cases the buttonholes occurred directly adjacent to the lid margin. Patient characteristics are given in Table 1; showing that the patients had multiple preoperated eyes. Erosion of conjunctiva occurred after a minimum of one and a maximum of 70 months after glaucoma drainage

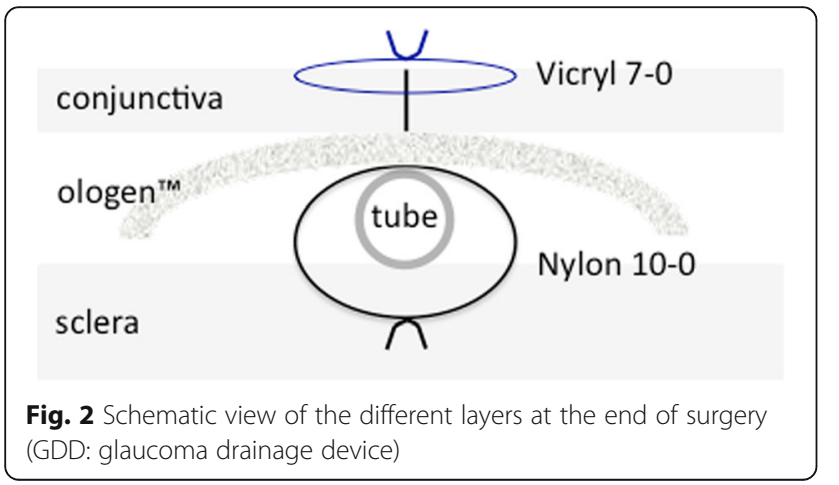

device surgery with a mean of $25.1 \pm 30.8$ months. We could not detect any ologen ${ }^{\text {Tm }}$ specific side-effects such as allergy or translocation of the implant on postoperative follow-up visits. No severe postoperative complications were detected and conjunctiva remained healthy and closed on follow-up.

The course of intraocular pressure changes and medication score is shown in Table 2. The mean follow-up time was $26.8 \pm 9.0$ months. Further glaucoma surgery was necessary in three cases: in one case (patient \#2) an additional glaucoma drainage device was used, while in two cases (patient \#4 \& \#6) additional cyclophotocoagulation was applied.

\section{Discussion}

Glaucoma drainage device surgery is a useful adjunct in the treatment of refractory glaucoma despite having a few serious complications [1, 11-13]. As a consequence of the results of the TVT study $[14,15]$, glaucoma drainage device surgery is now being used more frequently than in the past and at an earlier stage (typical situation: Pseudophakic eyes with one or two failed trabeculectomies). Since this surgical method is now carried out more frequently, an increasing number of typical sideeffects should be taken into consideration. One such complication is thinning of the conjunctiva directly above the tube with complete erosion of the overlying tissue [5]. This may result in leakage and is always an indication for revision surgery, as this entrance gate is a potential source of endophthalmitis [7].

The exact mechanism of conjunctival erosion remains unclear since, as far as could be seen, the implants and the tubes were correctly positioned. The buttonholes are probably formed either due to mechanical stress at the lid margin or due to the gap between the tube and sclera posterior to the scleral flap arising through the architecture of the glaucoma drainage devices near the basal plate.

To prevent conjunctival erosion, the tube should be patched during primary surgery and the patch covered with conjunctiva. The tube can be patched either with a scleral flap or with bovine pericardium, human sclera or other materials. The use of patched tubes has decreased the exposure rate from $30 \%$ to less than 5\% [5]. In our case series all tubes were patched with a scleral flap in primary surgery.

Should a penetrating defect in the conjunctiva nevertheless occur during follow-up, it can be difficult to achieve closure of conjunctiva. A few methods for closing these defects in the conjunctiva have been described previously: For direct suture of the defect and use of conjunctival autografts, the results in literature show different success rates: A simple conjunctival closure is inadequate [16]. Reports on conjunctival autografts and 
Table 1 Patient characteristics for the presented case series of eight patients

\begin{tabular}{llllll}
\hline$\#$ & Age [years] & Type of glaucoma & Preliminary surgeries & $\begin{array}{l}\text { Erosion of conjunctiva } \\
\text { after } x x \text { months }\end{array}$ & BCVA [LogMAR] \\
\hline P1 & 51 & Angle closure & IE, Phaco, ppV, TE & 70 & 0.20 \\
P2 & 49 & XFG & Phaco, TA, TE & 2 & 0.20 \\
P3 & 12 & Uveitic & Phaco, TE & 1 & 0.20 \\
P4 & 57 & Silicon oil & ppV, TE & 4 & 0.80 \\
P5 & 41 & Silicon oil & PpV, TE & 4 & 1.00 \\
P6 & 81 & Uveitic & Phaco, TE & 60 & Light perception \\
P7 & 18 & Uveitic & Phaco, ppV & 56 & 0.60 \\
P8 & 44 & Traumatic & $2 \times$ TE & 4 & 0.00 \\
Mean \pm SD & $44.1 \pm 21.8$ & & & $25.1 \pm 30.8$ & \\
\hline BCV & & & & \\
\hline
\end{tabular}

$B C V A$ best-corrected visual acuity, IE Iridectomy, Phaco Phacoemulsification, $p p V$ pars plana vitrectomy, SD standard deviation, $T A$ trabecular aspiration, $T E$ trabeculectomy, XFG Pseudoexfoliation glaucoma

conjunctival closure with a patch graft provided better results (Success rates: acellular human dermis patch graft: $83 \%$; autologous scleral lamellar graft: $100 \%)[5,16]$. Also good results have been reported with amniotic membranes and additional application of autologous serum in a few cases of conjunctival erosion (Three cases; $100 \%$ success; follow-up: 6-30 months) [17].

Table 2 Intraocular pressure and antiglaucomatous medication score preoperative and at different points of follow-up

\begin{tabular}{|c|c|c|c|c|}
\hline \multicolumn{5}{|c|}{ Intraocular pressure $[\mathrm{mmHg}]$} \\
\hline$\#$ & preOP & d1 & $12 \mathrm{~m}$ & Last follow-up (xx mo) \\
\hline P1 & 15 & 13 & 15 & 16 (24 mo) \\
\hline P2 & 19 & 23 & 15 & 13 (24 mo) \\
\hline P3 & 25 & 10 & 12 & 14 (24 mo) \\
\hline P4 & 17 & - & 15 & 9 (42 mo) \\
\hline P5 & 25 & 24 & 17 & 16 (24 mo) \\
\hline P6 & 19 & 11 & 19 & 19 (12 mo) \\
\hline P7 & 16 & 21 & 6 & 9 (28 mo) \\
\hline P8 & 14 & - & 12 & 19 (36 mo) \\
\hline Mean \pm SD & $18.8 \pm 4.2$ & $17.0 \pm 6,4$ & $13.9 \pm 3.9$ & $14.4 \pm 3.9$ \\
\hline \multicolumn{5}{|c|}{ Medication score } \\
\hline \# & preOP & d1 & $12 \mathrm{~m}$ & Last follow-up (xx mo) \\
\hline P1 & 2 & 2 & 0 & 0 (24 mo) \\
\hline P2 & 0 & 0 & 6 & 0 (24 mo) \\
\hline P3 & 10 & 0 & 5 & $4(24 \mathrm{mo})$ \\
\hline P4 & 6 & - & 6 & 0 (42 mo) \\
\hline P5 & 8 & 5 & 5 & 5 (24 mo) \\
\hline P6 & 0 & 0 & 6 & 6 (12 mo) \\
\hline P7 & 0 & 0 & 0 & 0 (28 mo) \\
\hline P8 & 3 & - & 3 & 4 (36 mo) \\
\hline Mean \pm SD & $3.6 \pm 3.9$ & $1.2 \pm 2.0$ & $3.9 \pm 2.6$ & $2.4 \pm 2.6$ \\
\hline
\end{tabular}

$12 \mathrm{~m}=12$ months after surgery; $\mathrm{d} 1=1$ day after surgery; IOP = intraocular pressure; MedScore = medication score; preOP = preoperative
Preliminary studies on bioengineered, biodegradable implants suggest that a porous collagen-glycosaminoglycane matrix (CGM; ologen ${ }^{\mathrm{Tx}}$ ) will reduce conjunctival contraction and promote formation of an almost normal subconjunctival stroma [18-20]. Moreover, the use of the $\operatorname{ologen}^{\text {tox }}$ implant was also described in primary glaucoma drainage device surgery as a patch with a good success rate [21]. This led us to try CGM in a single case of revision surgery after buttonhole formation on top of the drainage device tube [8]. After use of a total of eight CGM in revision surgery, we can confirm the persistent closure of conjunctival defects in all cases. No severe postoperative complications or CGM-specific side-effects were detected in our study series.

Except the patching of the tube with an ologen ${ }^{\mathrm{m}}$ implant, the lateral displacement of the tube also appears to be decisive in our approach. This prevents the previously damaged conjunctiva from contact with the tube.

\section{Conclusion}

Our case series shows that the described method with lateral displacement of the tube and patching with CGM is a possible alternative in revision surgery for repair of eroded conjunctiva overlying the tube of the glaucoma drainage device. Possible positive effects of the CGM are the avoidance of direct contact between the conjuctiva and the tube and the fact that CGM acts as a wound healing scaffold for structurally more normal tissue rather than structurally deficient scar tissue. Moreover, CGM probably minimizes movement of the conjunctiva in relation to the tube thus facilitating wound healing.

\section{Abbreviations}

5-FU: 5-fluoruracile; CGM: Collagen-glycosaminoglycane matrices; GDD: Glaucoma drainage device; IOP: Intraocular pressure; MMC: MitomycinC; TVT study: Tube versus trabecuectomy study 


\section{Acknoledgements}

No acknoledgement.

\section{Funding}

None to report.

\section{Availability of data and materials}

The datasets used and/or analysed during the current study are available from the corresponding author on reasonable request.

\section{Authors disclosure}

No external support.

\section{Authors' contributions}

Design and conception of the study: AR, AL, TD. Acquisition and analysis of data: AR, MA, RW, TD. Drafting and revising the manuscript: AR, AL, MA, RW TD. Final approval: AR, TD. All authors read and approved the final manuscript.

\section{Ethics approval and consent to participate}

Due to the retrospective study design an ethics approval for this case series was not necessary.

$\S 2$ (1) and (2) of the Statutes of the Ethics Committee of the University of Lübeck.

\section{Consent for publication}

Not applicable. Our manuscript does not contain any individual personal data.

\section{Competing interests}

The authors declare that they have no competing interests.

\section{Publisher's Note}

Springer Nature remains neutral with regard to jurisdictional claims in published maps and institutional affiliations.

\section{Author details}

'Department of Ophthalmology, University of Würzburg, Josef-Schneider-Str. 11, 97080 Würzburg, Germany. ${ }^{2}$ Center of Ophthalmology, University of Cologne, Cologne, Germany. ${ }^{3}$ Department of Ophthalmology, St. Martinus-Krankenhaus Düsseldorf, Düsseldorf, Germany. ${ }^{4}$ Department Of Ophthalmology, University of Muenster Medical Center, Muenster, Germany

Received: 3 June 2017 Accepted: 16 February 2018

Published online: 27 February 2018

\section{References}

1. Ayyala RS, Zurakowski D, Smith JA, Monshizadeh R, Netland PA, Richards DW, et al. A clinical study of the Ahmed glaucoma valve implant in advanced glaucoma. Ophthalmology. 1998;105:1968-76.

2. Lim KS, Allan BDS, Lloyd AW, Muir A, Khaw PT. Glaucoma drainage devices; past, present, and future. Br J Ophthalmol. 1998;82:1083-9.

3. Aslanides IM, Spaeth GL, Schmidt CM, Lanzl IM, Gandham SB. Autologous patch graft in tube shunt surgery. J Glaucoma. 1999:8:306-9.

4. Siegner SW, Netland PA, Urban RC Jr, Williams AS, Richards DW, Latina MA, et al. Clinical experience with the Baerveldt glaucoma drainage implant Ophthalmology. 1995;102:1298-307.

5. Heuer DK, Budenz D, Coleman A. Aqueous shunt tube erosion. J Glaucoma. 2001;10:493-6

6. DeBry PW, Perkins TW, Heatley G, Kaufman P, Brumback LC. Incidence of late-onset bleb-related complications following trabeculectomy with mitomycin. Arch Ophthalmol. 2002;120:297-300

7. Francis BA, DiLoreto DA Jr, Chong LP, Rao N. Late-onset bacteria endophthalmitis following glaucoma drainage implantation. Ophthalmic Surg Lasers Imaging. 2003;34:128-30.

8. Rosentreter A, Schild AM, Dinslage S, Dietlein TS. Biodegradable implant for tissue repair after glaucoma drainage device surgery. J Glaucoma. 2012;21: $76-8$

9. Stenzel KH, Miyata T, Rubin AL. Collagen as a biomaterial. Annu Rev Biophys Bioeng. 1974;3:231-53.
10. Jacobi PC, Krieglstein GK. Trabecular aspiration. A new mode to treat pseudoexfoliation glaucoma. Invest Ophthalmol Vis Sci. 1995:36:2270-6.

11. Goulet RJ 3rd, Phan AD, Cantor LB, WuDunn D. Efficacy of the Ahmed S2 glaucoma valve compared with the Baerveldt $250 \mathrm{~mm} 2$ glaucoma implant. Ophthalmology. 2008;115:1141-7.

12. Syed HM, Law SK, Nam SH, Li G, Caprioli J, Coleman A. Baerveldt-350 implant versus Ahmed valve for refractory glaucoma. A case-controlled comparison. J Glaucoma. 2004;13:38-45.

13. WuDunn D, Phan AD, Cantor LB, Lind JT, Cortes A, Wu B. Clinical experience with the Baerveldt $250 \mathrm{~mm} 2$ glaucoma implant. Ophthalmology. 2006;113: 766-72.

14. Gedde SJ, Schiffman JC, Feuer WJ, Herndon LW, Brandt JD, Budenz DL, Tube Versus Trabeculectomy Study Group. Treatment outcomes in the tube versus trabeculectomy (TVT) study after five years of follow-up. Am J Ophthalmol. 2012:153:789-803.

15. Gedde SJ, Herndon LW, Brandt JD, Budenz DL, Feuer WJ, Schiffman JC, Tube Versus Trabeculectomy Study Group. Postoperative complications in the tube versus trabeculectomy (TVT) study during five years of follow-up. Am J Ophthalmol. 2012;153:804-14.

16. Kalenak JW. Revision for exposed anterior segment tubes. J Glaucoma. 2010; 19:5-10.

17. Ainsworth G, Rotchford A, Dua HS, King AJ. A novel use of amniotic membrane in the management of tube exposure following glaucoma tube shunt surgery. Br J Ophthalmol. 2006:90:417-9.

18. Chen HS, Ritch R, Krupin T, Hsu WC. Control of filtering bleb structure through tissue bioengineering: an animal model. Invest Ohthalmol Vis Sci. 2006:47:5310-4.

19. Hsu WC, Ritch R, Krupin T, Chen HS. Tissue bioengineering for surgical bleb defects: an animal study. Graefes Arch Clin Exp Ophthalmol. 2008;246:70917.

20. Hsu WC, Spilker MH, Yannas IV, Rubin PA. Inhibition of conjunctival scarring and contraction by a porous collagen-glycosaminoglycan implant. Invest Ophthalmol Vis Sci. 2000:41:2404-11.

21. Stephens JD, Sarkisian SR Jr. The use of collagen matrix (Ologen) as a patch graft in glaucoma tube shunt surgery, a retrospective chart review. F1000Res. 2016;5:1898.

\section{Submit your next manuscript to BioMed Central and we will help you at every step:}

- We accept pre-submission inquiries

- Our selector tool helps you to find the most relevant journal

- We provide round the clock customer support

- Convenient online submission

- Thorough peer review

- Inclusion in PubMed and all major indexing services

- Maximum visibility for your research

Submit your manuscript at www.biomedcentral.com/submit 